Two years ago, in a study ("The BBC's medical programmes and their effects on lay audiences") for the GAC by the department of science and features, it was stated that "the responsibilities of this department, where medicine is concerned, are no different from those which apply to other scientific topics dealt with in our programmes." This tidy façade I thought to be a product of superficial reasoning. It takes no account of the connotations and imponderables in medicine or of the unique influence and immediacy of matters medical on the attitudes and lives of the lay public.

The approach to medicine could not have been thought out. How else to explain "It is programmes that make policy, not policy that makes programmes" ?-a remarkable utterance by the head of science and features department at the Royal Society of Medicine in 1976. This slick thought-dampener, far from being concealed, was flaunted later before the GAC and was accepted. Presumably it is still dogma in medical broadcasting.

My respect and admiration for the $\mathrm{BBC}$ are undimmed by the arguments you have published, which tend to focus on irritating superficialities. It is deeper, structural flaws that should be examined and corrected, preferably by the medical profession and $\mathrm{BBC}$ together.

JOHN APLEY

Bath

\section{Treatment of tuberculosis}

SIR,-I in turn am surprised at the different emphases in treating tuberculosis in the Liverpool School of Tropical Medicine (Dr D Robinson, 22 April, p 1053).

(1) I believe that where possible treatment should be based on the results of controlled trials and that inspiration, eccentricity, or years of experience are insufficient as alternative bases.

(2) I did not assume that the effects of $M y c o-$ bacterium tuberculosis and the syndrome of mycobacterial diseases are "the same thing." Indeed, the brief reference to opportunist mycobacteria simply drew attention to the fact that they behave differently. To discuss their treatment more fully would have required more space than the Editor would allow.

(3) I have never before heard tuberculosis referred to as a "subdisease" It must rank as the most important and fatal non-disease in history. Anyone who feels that the laboratory plays the major role in the management of this subdisease must have little practical experience of dealing with patients suffering from it. Perhaps that is why Dr Robinson is not aware that most doctors and indeed many laymen actually regard it as a fully fledged disease. Sensible clinicians do, however, work in close contact with sensible bacteriologists in managing the condition.

(4) The confusion does not appear to be in the paragraph but in the mind of Dr Robinson. I feel, and others more authoritative and experienced than myself seem to agree, that contacts should be investigated. Not to do so would allow cases to go undetected in the community.

(5) The side effects of the drugs are listed in my article and further information is available and referred to. Isoniazid-induced hepatitis is, as stated, uncommon in Britain. My article makes clear that follow-up of patients is essential and that drug side effects are a problem to be aware of Did Dr Robinson read it?

(6) Rifampicin has already shortened the standard regimen and the evidence is quoted. There are few contraindications to its use and it has now been used widely in pregnancy. Dr Robinson is badly out of date.

(7) Practice in Britain has now relegated strepto- mycin to a somewhat less important role, though, as I state, it remains a first-line drug. Ethionamide and pyrazinamide are generally used as second-line drugs and both are mentioned in my article.

(8) Sputum culture is mentioned as a keystone in the diagnosis and is an important aspect of follow-up. The primary role in the management of tuberculosis, and with it the responsibility, should be that of the physician. A nurse or health worker is an invaluable aid in this but is surely not able to take primary responsibility.

I reply to all Dr Robinson's points because I believe he has over-reacted to my article and is almost entirely wrong in what he says. I do not wish your readers to be misled by his letter and would refer them back to my article and the suggested further reading to judge for themselves.

ANTHONY SEATON

Institute of Occupational Medicine,

Institute of

\section{Diuretics in the elderly}

SIR,-Your timely reminder of the dangers of prescribing diuretics to elderly patients (29 April, p 1092) fails to mention the problems of magnesium deficiency. That increased excretion of magnesium occurs has been known for some time ${ }^{1}$ and symptomatic hypomag nesaemia has also been described." The symptoms encountered in magnesium depletion include confusion, ataxia, tremor, nausea, and palpitations, all of which commonly occur in the elderly. Recently Ibrahim and Sutcliff $^{3}$ showed a high incidence of symptomatic magnesium deficiency in the elderly which responded well to replacement therapy.

As a number of elderly patients receiving diuretics may also be having digoxin it is important to remember that hypomagnesaemia is associated with an increased sensitivity to digoxin $^{4}$ as well as with primary cardiac arrhythmias. 5

I would therefore suggest that magnesium depletion should always be considered in elderly patients who become unwell, especially if on diuretics.

University Department of Medicine, Royal Hospital,

' Smith, W O, et al, Clinical Research, 1959, 7, 162 Wacker, W E C, and Parisi, A F, New England October 1977, p 6 .

- Seller, R H, American Heart fournal, 1971, 82, 551.

Chadda, K D, Edgar, L, and Gupta, P, American fournal of Cardiology, 1973, 31, 98.

SIR,-Once again Slow-K is quoted as cause of ulceration of the small intestine (leading article, 29 April, p 1092). This is surely an extremely rare event and is almost always associated with pre-existing gut stricture or slow intestinal transit time, as in the reference cited by you. ${ }^{1}$ Bearing in mind that approximately 600 million tablets of Slow-K are dispensed in the United Kingdom every year, Slow-K must be just about the best tolerated preparation on the market. It must not be confused with enteric-coated tablets.

DENIS BURLEY Head of Medical Services,

Horsham, w Sussex Ciba Laboratories 'Farquharson-Roberts, M A, Giddings, A E B, and
Nunn, A J, British Medical fournal, 1975, 3, 206.
Sulphinpyrazone after myocardial infarction

SIR,-In response to your leading article (15 April, p 941) concerning rhythm abnormalities in the sulphinpyrazone cardiac infarction trial I should like to quote from our original paper ${ }^{1}$ :

"Although, as shown in table 2, more patients receiving placebo (111) than patients receiving sulphinpyrazone (83) had cardiac rhythm abnormalities at the first visit, deaths among patients with rhythm abnormalities (six in the placebo, and two in the sulphinpyrazone group) represented only $12 \%$ of all deaths; furthermore, the presence of abnormalities of rhythm at entry into the study did not appear to be a significant risk factor since $5.4 \%$ of placebo-treated patients with such abnormalities died as compared to $6.0{ }^{\circ}$ of placebo patients without them."

In addition, we have also calculated the death rates per 28-day exposure period $\times 1000$. The findings are shown in the table:

\begin{tabular}{|c|c|c|c|}
\hline \multirow{2}{*}{\multicolumn{2}{|c|}{ Treatment group }} & \multicolumn{2}{|c|}{ Rhythm abnormalities } \\
\hline & & No & Yes \\
\hline $\begin{array}{l}\text { Placebo ... } \\
\text { Sulphinpyrazone } \\
\text { Combined }\end{array}$ & $\begin{array}{l}\cdots \\
\therefore\end{array}$ & $\begin{array}{l}7 \cdot 4(38)^{*} \\
4 \cdot 0(23) \\
5 \cdot 7(61)\end{array}$ & $\begin{array}{l}6.6(6) \\
2.9(2) \\
5.0(8)\end{array}$ \\
\hline
\end{tabular}

*Values in parentheses are actual numbers of deaths.

The statistical analyses employed in this trial (Cox model) permit adjustment in balances of entry criteria. The possible imbalance of rhythm abnormalities was thus adjusted for and did not account for any significant difference between unadjusted and adjusted $P$ values.

The final report of this trial will include details of all aspects of electrocardiograms in so far as our data base will permit.

SydNEY H KaNE for Policy Committee,
Anturane Reinfarction Trial

Pharmaceuticals Division, Ciba-Geigy Corporation,
Summit, New Jersey

${ }^{1}$ Anturane Reinfarction Trial Research Group, New England fournal of Medicine, 1978, 298, 289.

Plasma urate changes in pre-eclampsia

SIR,-Mr W Dunlop and Mr J M Davison (25 March, p 786) query our use of plasma urate increments (25 February, p 467) to define grades of severity of pre-eclampsia. While we accept their general point that small increases of plasma urate cannot be used clinically to diagnose patients with preeclampsia, their claim that these changes may be "physiological" is not necessarily valid That plasma urate levels above $350 \mu \mathrm{mol} / 1$ $(6 \mathrm{mg} / 100 \mathrm{ml})$ indicate significant preeclampsia has always implied that antenatal increases of plasma urate have already occurred. This is also clearly demonstrated in our recent paper. A priori in the development of preeclampsia there must be a time when plasma urate levels show small rises above an earlier baseline reading. The morbidity of this prodromal stage would not be expected to be high because in many women the plasma urate changes either coincide with or precede the elevation of the blood pressure. When elevation of the plasma urate occurs at or near term pregnancy-induced hypertension may not arise as the process will normally be cut short by spontaneous or induced delivery. 